\title{
Seasonal depression of fertility in hot climates as influenced by production level and temperature humidity stress
}

\author{
M.M. HEIMAN \\ «On», A.I. Coop. Sarid, Israel
}

NR rates of 275719 inseminations in 124 high producing large herds in 4 years revealed a severe depression of fertility in the hot season, whereas 206829 inseminations in moderately producing small herds did not show such a depression. The combined influences of 2 stresses, yield and climate, cause the depression.

A study on high yielding herds, during 3 years in 2 types of climate was carried out. In 34 herds with 12625 cows in coastal areas with less high temperature but higher humidity, fertility depression was stronger in each of the 3 years, than in 35 herds with 11540 cows in inland areas with higher temperature but lower humidity.

Seasonalizing of inseminations and providing of an appropriate microclimate are the answers to the problem of climatic stress.

\section{Milk production in India of imported and local born Braunvieh cows}

\author{
W. KROPF *, M. MENZI** and W. von SIEBENTHAL *** \\ * Institute of Animal Production, ETH Zurich, Switzerland \\ ** Agricultural Consultant, 3600 Thun, Switzerland \\ *** AI Centre, Mülligen, Switzerland
}

Milk yields in 1st and 2nd lactation, first calving interval (FCI), age at first (AFC) and at second calving (ASC) of two imported Braunvieh groups (IMP 1 and IMP 2) and their offsprings born in India (Indian born) have been compared. Indian born heifers calved at 1013 days of age (Switzerland 1978, 1979: 1019 days). 305-days milk yields in 1st resp. 2nd lactation were about $2355 \mathrm{~kg}$ and $2612 \mathrm{~kg}$ (IMP 1), $2125 \mathrm{~kg}$ and $2558 \mathrm{~kg}$ (IMP 2) and 1794 and $2387 \mathrm{~kg}$ (Indian born), and were inferior to performances realized in Switzerland $(1978,1979$ : 1st lact. : $3353 \mathrm{~kg} ;$ 2nd lact. : $4169 \mathrm{~kg})$. The low first standard lactation of Indian born cows is a consequence of an extensive raising. FCI for IMP 1 (455 days) and IMP 2 (475 days) was longer than in Switzerland (1978, 1979 : 410 days), which indicates that fertility is lower during acclimatization.

\section{Milk production of imported Braunvieh, Holsfein and Brown Swiss cows in the tropical lowlands of Bolivia}

\author{
W. KROPF and M. HAUTLE * \\ * Institute of Animal Production, ETH Zurich, Switzerland
}

The 100-, 200- and 305-days milk yield (305 DMY) of 172 Brown Swiss (BS, imported from the U.S.A.), 197 Holstein (HO, from Argentina) and 72 Braunvieh (BV, from Switzerland) imported as pregnant heifers to Bolivia (near Sta Cruz) are analysed, 1st and 2nd 305 DMY were about $3376 \mathrm{~kg}$ and $3413 \mathrm{~kg}$ (HO), $2903 \mathrm{~kg}$ and $2804 \mathrm{~kg}$ (BS) and $2707 \mathrm{~kg}$ and $2813 \mathrm{~kg}(\mathrm{BV})$. In the 1st lactation BS perform $58 \mathrm{p} .100$ and BV $77 \mathrm{p} .100$ of the 305 DMY of contemporaries in the country of origin. 305 DMY of HO are superior to those of BV and BS. There is no increase in 305 DMY from the 1st to the 2nd lactation for all three breeds. 